\title{
Polyphenol composition and biological activity of Thymus citriodorus and Thymus vulgaris: Comparison with endemic Iberian Thymus species
}

\author{
Meriem Taghouti ${ }^{\mathrm{a}, \mathrm{b}, 1}$, Carlos Martins-Gomes ${ }^{\mathrm{a}, \mathrm{b}, 1}$, Luís M. Félix ${ }^{\mathrm{a}}$, Judith Schäfer ${ }^{\mathrm{c}}$, \\ João A. Santos ${ }^{\mathrm{a}, \mathrm{d}}$, Mirko Bunzel ${ }^{\mathrm{c}}$, Fernando M. Nunes ${ }^{\mathrm{b}, \mathrm{e}, *, 2}$, Amélia M. Silva ${ }^{\mathrm{a}, \mathrm{f}, 2, *}$ \\ ${ }^{a}$ Centre for Research and Technology of Agro-Environmental and Biological Sciences (CITAB), University of Trás-os-Montes and Alto Douro (UTAD), Quinta de Prados, \\ 5001801 Vila Real, Portugal \\ ${ }^{\mathrm{b}}$ Food and Wine Chemistry Lab, Chemistry Research Centre Vila Real (CQ-VR), UTAD, Quinta de Prados, 5001801 Vila Real, Portugal \\ ${ }^{\mathrm{c}}$ Department of Food Chemistry and Phytochemistry, Institute of Applied Biosciences, Karlsruhe Institute of Technology (KIT), Adenauerring $20 a$, 76131 Karlsruhe, \\ Germany \\ ${ }^{\mathrm{d}}$ Department of Physics, School of Sciences and Technology, UTAD, Quinta de Prados, 5001801 Vila Real, Portugal \\ ${ }^{\mathrm{e}}$ Department of Chemistry, School of Life Sciences and Environment, UTAD, Quinta de Prados, 5001801 Vila Real, Portugal \\ ${ }^{\mathrm{f}}$ Department of Biology and Environment, School of Life Sciences and Environment, UTAD, Quinta de Prados, 5001801 Vila Real, Portugal
}

\section{A R T I C L E I N F O}

Chemical Compound of the articles: Apigenin (PubChem CID: 5280443)

Caffeic acid (PubChem CID: 689043)

Chrysoeriol (Pubchem CID 5280666)

Eriodictyol (Pubchem CID 440735)

Luteolin (PubChem CID: 5280445)

Rosmarinic acid (PubChem CID: 5281792)

Salvianolic acid A (PubChem CID: 5281793)

Salvianolic acid I (Pubchem CID 10459878)

Salvianolic acid K (Pubchem CID 10482829)

Keywords:

Thymus L. species

Thymus $\times$ citriodorus

Thymus vulgaris

Phenolic compound profiling

Antioxidant activity

Anti-proliferative activity

Caco-2

HepG2

\begin{abstract}
A B S T R A C T
The polyphenol compositions of Thymus $\times$ citriodorus and Thymus vulgaris extracts as obtained by exhaustive hydroethanolic (HE) extraction and aqueous decoction (AD) were compared. In addition, their compositions and bioactivities were compared to those of Thymus pulegioides and Thymus mastichina, grown under the same edaphoclimatic conditions, and Thymus carnosus. Rosmarinic acid was the most abundant polyphenol followed by luteolin-hexuronide, salvianolic acids I and K. Cluster analysis suggests a similarity of the polyphenol composition of T. citriodorus and T. vulgaris. A significant antioxidant activity was observed and correlated with their polyphenol levels. The same being observed for the higher anti-proliferative activity/cytotoxicity of HE extracts on Caco-2 and HepG2 cells as compared to AD extracts. Significant association between the total phenolic compounds with the anti-proliferative activity, for both cell lines, was observed. These results support the importance of salvianolic acids levels in Thymus extracts and their in vitro anti-proliferative/cytotoxic activities.
\end{abstract}

\section{Introduction}

In recent years, a growing interest in phenolic compounds as natural ingredients for food additives and health promoters has been noted and, as a result, there has been a great deal of interest in further investigation and characterization of various traditionally used plant species.
Plants from the Lamiaceae family, such as the genus Thymus L., have been suggested to contribute to several potential health benefits by their reported anti-inflammatory (Khouya et al., 2015) and anti-proliferative (Martins-Gomes, Souto, Cosme, Nunes, \& Silva, 2019; Taghouti et al., 2018) as well as anti-microbial (Leal et al., 2017; Nabavi et al., 2015) and anti-oxidant (Kindl, Blazekovic, Bucar, \&

* Corresponding authors at: Department of Biology and Environment (DeBA), University of Trás-os-Montes and Alto Douro (UTAD), Quinta de Prados, 5001-801 Vila Real, Portugal (A.M. Silva), CQ-VR, Chemistry Research Centre, Chemistry Department, University of Trás-os-Montes and Alto Douro, Quinta de Prados, 5000801, Vila Real, Portugal (F.M. Nunes).

E-mail addresses: fnunes@utad.pt (F.M. Nunes), amsilva@utad.pt (A.M. Silva).

${ }^{1}$ Equal contribution as first author.

${ }^{2}$ Equal contribution as last author. 
Vladimir-Knezevic, 2015) potentials, with the latter two being also suitable to increase food shelf life. Concerning Thymus plants, several species are widely used as culinary herbs, condiments (e.g. Thymus vulgaris L.), herbal medicinal products, herbal teas or syrups (e.g. Thymus $\times$ citriodorus (Pers.) Schreb., Thymus pulegioides L., Thymus mastichina L.), based on their organoleptic, preservative and medicinal properties (e.g. (O. R. Pereira, Macias, Perez, Marin, \& Cardoso, 2013; Taghouti et al., 2018).

Thymus $\times$ citriodorus (Pers.) Schreb. (T. citriodorus) or lemonscented thyme is considered to be a hybrid between T. pulegioides and $T$. vulgaris (Lundgren \& Stenhagen, 1982). T. citriodorus is native from Southern Europe, cultivated in the Mediterranean area and, due to its lemon flavour, is mainly used for culinary purposes, either as seasoning or as herbal tea (Rita, Pereira, Barros, \& Ferreira, 2018). Several bioactivities have been attributed to this species, namely anti-oxidant and cytoprotective effects (Pereira et al., 2013) as well as anti-bacterial and anti-radical scavenging activity (Sacchetti et al., 2005). These bioactivities might be intrinsically correlated with its chemical composition, although data to support this are still scarce. The reported chemical composition of non-volatile extracts of T. citriodorus includes rosmarinic acid, as the major compound, cinnamic acid derivatives, such as caffeic acid, and derivatives of luteolin, eriodictyol, quercetin, chrysœriol, and apigenin (Pereira, Peres, Silva, Domingues, \& Cardoso, 2013; Rita et al., 2018).

Thymus vulgaris L. (T. vulgaris) or common thyme is the most often used and studied species within the Thymus genus. T. vulgaris is an herbaceous, perennial aromatic and medicinal plant, commonly consumed as herbal infusion and as a condiment and spice (flavouring agent) (Pereira et al., 2016). T. vulgaris is mostly cultivated for food, pharmaceutical, and cosmetic industries and it is listed in current editions of European Pharmacopoeia, US Pharmacopeia, and in other official papers (Gavarić et al., 2015). Its essential oil is characterized by a high chemical polymorphism, although thymol/carvacrol chemotypes are the most often reported ones (Thompson, Chalchat, Michet, Linhart, \& Ehlers, 2003). Apart from essential oils, T. vulgaris is a rich source of bioactive compounds such as rosmarinic acid and its derivatives, with rosmarinic acid being reported as the main component (Chizzola, Michitsch, \& Franz, 2008; Pereira et al., 2016) along with luteolin, apigenin, caffeic acid and their derivatives, and eriodictyol (Pacifico et al., 2016; Pereira et al., 2016). Several in vitro bioactivities of different $T$. vulgaris extracts (prepared with different solvents and methods) have been reported, such as anti-oxidant and DNA-protective activity against oxidation, anti-microbial (Kozics et al., 2013; Martins et al., 2015; Nikolić et al., 2014), anti-inflammatory (Vigo, Cepeda, Gualillo, \& Perez-Fernandez, 2004), and anti-tumoral potentials (Pacifico et al., 2016).

Although there is already a basic chemical profile of these species, an in-depth compositional analysis based on an exhaustive extraction (e.g. hydroethanolic exhaustive extraction (Martins-Gomes et al., 2018)) is required. Also, a correlation between chemical composition and bioactivities is needed for further applications as functional foods and/or as sources of bioactive ingredients. The importance of functional foods, nutraceuticals, and other natural health products has been well recognized in connection with health promotion and disease risk reduction (Shahidi, 2009). Functional foods are similar in appearance to conventional foods being consumed as part of the normal diet with demonstrated physiological benefits and can reduce the risk of chronic disease beyond basic nutritional functions, including maintenance of gut health (Food and Agriculture Organization of the United Nations (FAO), authors Report on Functional Foods, Food Quality and Standards Service (AGNS) 2007 [(accessed on 21 March 2020)]). A nutraceutical is "a food or part of a food that provides benefits health in addition to its nutritional content" (Daliu, Santini, \& Novellino, 2019). Thus the consumption of these Thymus species (T. vulgaris and T. citriodorus), either fresh or dried, as condiments, herbal teas (widely sold by several companies) or in other preparations, constitute a source of molecules with potential health promoting effects.

Therefore, this study aimed to characterize the chemical composition of two extracts of T. citriodorus and of T. vulgaris, one obtained by aqueous decoction and the other one by exhaustive hydroethanolic extraction. Furthermore, the present study aimed to deepen the scientific knowledge regarding phenolic profile, antioxidant activity by using three antioxidant methods, and in vitro anti-proliferative activity using Caco-2 (human colon adenocarcinoma cell line) and HepG2 (human hepatocellular carcinoma cell line) cells. These cell lines were chosen because this model mimics (as an in vitro approach) the effect of plant components' interaction with intestinal tract tissues during absorption and with hepatic tissues, as a result of the first-pass effect of absorbed components.

\section{Materials and methods}

\subsection{Standards and reagents}

Commercial standards of salvianolic acid A, apigenin, rosmarinic acid, catechin, luteolin, and ursolic acid were purchased from SigmaAldrich/Merck (Algés, Portugal). Caffeic acid and eriodyctiol-(7)-Ohexoside were obtained from Extrasynthese ${ }^{\circledR}$ (Genay, France). Oleanolic acid was obtained from Santa Cruz Biotechnology Inc (Frilabo, Porto, Portugal). Dulbecco's Modified Eagle Medium (DMEM), sodium pyruvate, penicillin, streptomycin, versene, L-glutamine, Trypsin-EDTA, and foetal bovine serum (FBS) were obtained from Gibco (Alfagene, Lisboa, Portugal). Alamar Blue ${ }^{\circledast}$ was obtained from Invitrogen, Life-Technologies (Alfagene, Lisboa, Portugal). Methanol, ethanol, formic acid, and acetic acid were HPLC or MS grade according to the analysis and were purchased from Sigma-Aldrich/Merck (Algés, Portugal). Sodium nitrite, 2,2-azino-bis (3-ethylbenzothiazoline-6-sulfonic acid) diammonium salt (ABTS), ( \pm )-6-hydroxy-2,5,7,8-tetramethylchromane-2-carboxylic acid (Trolox), sodium nitroprusside, sulfanilamide, $N$-(1-naphthyl)ethylenediamine dihydrochloride, potassium persulfate, Folin-Ciocalteu's reagent, ethylenediaminetetraacetic acid (EDTA), ascorbic acid, aluminum chloride (III), sodium molybdate, trichloroacetic acid (TCA), thiobarbituric acid (TBA), 2deoxy-D-ribose, and hydrogen peroxide (30\% solution) were obtained from Sigma-Aldrich/Merck (Algés, Portugal). Other salts and reagents not mentioned were obtained from Sigma-Aldrich/Merck (Algés, Portugal).

\subsection{Plant material}

T. citriodorus and T. vulgaris aerial parts (upper part of stems and their leaves) were kindly supplied by ERVITAL ${ }^{\circledR}$ (Plantas Aromáticas e Medicinais, Lda; Mezio, Viseu, Portugal at $40^{\circ} 58^{\prime} 47.4^{\prime \prime} \mathrm{N} 7^{\circ} 53^{\prime} 43.3^{\prime \prime} \mathrm{W}$ ). Plants were harvested in the production fields of ERVITAL, from the plants used by ERVITAL for the production of herbal infusions and condiments for human consumption. Small portions from fresh plants (50 to 75 plants), grown under organic farming practice, were harvested in October 2014 (post-blooming, end fructification stage). A sample of each plant material was used for authentication by the Botanical Garden office at the University of Trás-os-Montes and Alto Douro (UTAD, Vila Real, Portugal), and a voucher specimen was deposited (HVR22054 to Thymus vulgaris L. and HVR21489 to Thymus $\times$ citriodorus L.). Immediately after the harvest, plants were rinsed with distilled water, weighted, and frozen $\left(-20{ }^{\circ} \mathrm{C}\right)$. After lyophilization (Dura Dry TM $\mu$ P freeze-drier; $-45{ }^{\circ} \mathrm{C}$ and 250 mTorr), the samples were properly stored until further extraction and analysis.

\subsection{Preparation of extracts}

The lyophilized aerial parts of T. citriodorus and T. vulgaris were ground to a very fine powder (using a coffee mill) and extracted according to two extraction methods: aqueous decoction (AD), aiming to 
mimic human consumption as herbal tea, infusion or condiment, and exhaustive hydroethanolic (HE) extraction, a method optimized to obtain all the extractable compounds within the plant material, as detailed in Martins-Gomes et al. (2018). In both extraction methods, $0.5 \mathrm{~g}$ of plants material (lyophilized and ground) were used. AD was performed by adding distilled water $(150 \mathrm{~mL})$ to the plant material; the mixture was heated up and boiled, under agitation, for $20 \mathrm{~min}$. After cooling, the volume was reduced to one-third by concentration in a rotary evaporator $\left(35{ }^{\circ} \mathrm{C}\right)$, and the extracts were then lyophilized, weighed to calculate the yields and properly stored until further analysis. HE exhaustive extraction was performed as a three-step sequential extraction. To the plant material, $50 \mathrm{~mL}$ of an $80 \%$ ethanol solution ( $\mathrm{v} / \mathrm{v}$, in water) were added. The mixture was agitated for $1 \mathrm{~h}$ (orbital shaker, $150 \mathrm{rpm}$, room temperature) and then centrifuged $\left(7000 \mathrm{rpm}, 4{ }^{\circ} \mathrm{C}\right.$; for $5 \mathrm{~min}$ (Sigma Centrifuges 3-30 K, St. Louis, MO, USA)). The supernatant was filtered and collected, followed by the addition of another $50 \mathrm{~mL}$ of $80 \%$ ethanol to the pellet. The extraction was repeated three times, and all supernatants were combined. In both extraction methods, the extracts were filtered twice (first through Whatman $n^{\circ} 4$ filter and then through $1.2 \mu \mathrm{m}$ fiberglass filter (VWR International Ltd., Alfragide, Portugal)) and then concentrated in a rotary evaporator $\left(35^{\circ} \mathrm{C}\right)$, also aiming to remove the ethanol used in HE extraction. Extracts were then lyophilized, weighed to calculate the yields and properly stored until further analysis.

\subsection{Total phenolic compound content}

The Folin-Ciocalteau method was used to assess the total content of phenolic compounds (TPC). To T. citriodorus and T. vulgaris extracts ( $1 \mathrm{~mL} ; 0.1 \mathrm{mg} / \mathrm{mL}$ ) were added $0.5 \mathrm{~mL}$ of Folin-Ciocalteau reagent, $1 \mathrm{~mL}$ of sodium carbonate $\left(\mathrm{Na}_{2} \mathrm{CO}_{3} ; 7.5 \%, \mathrm{w} / \mathrm{v}\right)$, and the volume was adjusted to $10 \mathrm{~mL}$ with distilled water. The mixture was incubated for $1 \mathrm{~h}$ at room temperature, and the absorbance was read at $725 \mathrm{~nm}$ using a spectrophotometer (PerkinElmer, Lambda 25 UV/VIS Spectrometer) (Ferreira, Silva, \& Nunes, 2018; Machado, Felizardo, Fernandes-Silva, Nunes, \& Barros, 2013). Caffeic acid was used as standard, and TPC was expressed as caffeic acid equivalents (mg CA eq/g lyophilized plant or mg CA eq/g extract).

\subsection{Total flavonoid content}

Total flavonoid content (TFC) was determined as described by Jia, Tang, and Wu (1999), using the aluminum chloride $\left(\mathrm{AlCl}_{3}\right)$ colorimetric method. To T. citriodorus and T. vulgaris extracts solution $(1 \mathrm{~mL}$; $0.5 \mathrm{mg} / \mathrm{mL}), 150 \mu \mathrm{L}$ of an aqueous sodium nitrite solution $\left(\mathrm{NaNO}_{2} ; 5 \%\right.$, $\mathrm{w} / \mathrm{v}$ ) was added. After a short incubation ( $5 \mathrm{~min}$, room temperature), $150 \mu \mathrm{L}$ of an $\mathrm{AlCl}_{3}$ solution $(10 \%, \mathrm{w} / \mathrm{v})$ was added. After 6 min incubation, $1 \mathrm{~mL}$ of a sodium hydroxide solution $(\mathrm{NaOH} ; 1 \mathrm{M})$ was added, and the absorbance was read at $510 \mathrm{~nm}$. Catechin was used as standard, and TFC was expressed as mg catechin equivalents (mg C eq/g lyophilized plant or $\mathrm{mg} \mathrm{C}$ eq/g extract).

\subsection{Total ortho-diphenol content}

Ortho-diphenol (ODP) content was determined as described by Machado et al. (2013), using the sodium molybdate colorimetric method. To T. citriodorus and T. vulgaris extracts ( $4 \mathrm{~mL} ; 0.1 \mathrm{mg} / \mathrm{mL}$ ), $1 \mathrm{~mL}$ of sodium molybdate solution $\left(\mathrm{Na}_{2} \mathrm{MoO}_{4} ; 5 \%\right.$, w/v) was added. The mixture was incubated ( $15 \mathrm{~min}$, room temperature), and the absorbance was measured at $370 \mathrm{~nm}$. Caffeic acid was used as standard, and ODP content was expressed as mg caffeic acid equivalents (mg CA eq/g lyophilized plant or mg CA eq/g of extract).

\subsection{In vitro antioxidant activity assessment}

\subsubsection{ABTS radical cation (ABTS ${ }^{+}$) scavenging assay}

$\mathrm{ABTS}^{+\cdot}$ scavenging assay was performed as described by Machado et al. (2013). To produce $\mathrm{ABTS}^{+}$, equal volumes of ABTS solution (2,2azino-bis(3-ethylbenzothiazoline-6-sulfonic acid) diammonium salt; $7 \mathrm{mM}$ in water) and potassium persulfate $\left(\mathrm{K}_{2} \mathrm{~S}_{2} \mathrm{O}_{8} ; 2.45 \mathrm{mM}\right.$ in water) were mixed and allowed to react for 15-16 h (in the dark, room temperature). The mixture was diluted using acetate buffer $(20 \mathrm{mM}, \mathrm{pH}$ 4.5) to obtain an absorbance of $0.700 \pm 0.02$ (at $734 \mathrm{~nm}$ ). To assess the scavenging activity of $T$. citriodorus and T. vulgaris extracts, ABTS ${ }^{+}$ solution $(2 \mathrm{~mL}$ ) was added to extracts ( $200 \mu \mathrm{L} ; 0.1 \mathrm{mg} / \mathrm{mL})$, followed by $15 \mathrm{~min}$ of incubation, after which the absorbance was read at $734 \mathrm{~nm}$. Trolox (( \pm )-6-hydroxy-2,5,7,8-tetramethylchromane-2-carboxylic acid) was used as a standard antioxidant. The scavenging potential was expressed as Trolox equivalents (mmol Trolox/g lyophilized plant or mmol Trolox/g extract).

\subsubsection{Hydroxyl radicals scavenging assay}

Hydroxyl radical $\left({ }^{\circ} \mathrm{OH}\right)$ scavenging activity was performed as described by Taghouti et al. (2018). Equal volumes (100 $\mu \mathrm{L})$ of deoxyribose $(20 \mathrm{mM})$, iron (II) chloride $\left(\mathrm{FeCl}_{2} ; 1 \mathrm{mM}\right)$, ascorbic acid (1 mM), and hydrogen peroxide $\left(\mathrm{H}_{2} \mathrm{O}_{2} ; 10 \mathrm{mM}\right)$ were added to $0.5 \mathrm{~mL}$ of $T$. citriodorus and T. vulgaris extract solutions $(0.1 \mathrm{mg} / \mathrm{mL})$, followed by the addition of $400 \mu \mathrm{L}$ of phosphate buffer solution ( $20 \mathrm{mM}$; pH 7.4). A second set of samples was prepared following the protocol described above, but with the addition of EDTA $(100 \mu \mathrm{L} ; 1 \mathrm{mM})$. After $1 \mathrm{~h}$ of incubation at $37{ }^{\circ} \mathrm{C}, 1.5 \mathrm{~mL}$ of TBA (5\%, in $10 \%$ TCA) were added, followed by $15 \mathrm{~min}$ of incubation at $100{ }^{\circ} \mathrm{C}$. Absorbance was read at $532 \mathrm{~nm}$. A blank (same mixture as described above with, however, distilled water $(0.5 \mathrm{~mL})$ replacing the extract solutions) was used as control. The ${ }^{\circ} \mathrm{OH}$ scavenging activity was expressed as percentage inhibition using equation 1 (Eq. 1):

Inhibition $(\%)=\frac{\text { Blank }(\mathrm{abs})-\text { Sample }(\mathrm{abs})}{\operatorname{Blank}(\mathrm{abs})} \times 100$

\subsubsection{Nitric oxide radical scavenging assay}

Nitric oxide radical (NO) scavenging activity was performed as described by Sreejayan and Rao (1997). NO ${ }^{*}$ was produced from a sodium nitroprusside solution ( $5 \mathrm{mM}$; in phosphate buffer $\left(0.1 \mathrm{M} \mathrm{H}_{3} \mathrm{PO}_{4}\right.$; $\mathrm{pH}$ 7.4)) that was oxygenated by purging with air for $15 \mathrm{~min}$. To $T$. citriodorus and T. vulgaris extracts $(0.5 \mathrm{~mL} ; 1 \mathrm{mg} / \mathrm{mL}), 4.5 \mathrm{~mL}$ of sodium nitroprusside solution was added, and the mixture was incubated for $2 \mathrm{~h}$ at $35^{\circ} \mathrm{C}$. $\mathrm{NO}^{\circ}$ was then quantified by using the Griess colorimetric assay. To $1 \mathrm{~mL}$ of the previous mixture (sample + sodium nitroprusside solution) $1 \mathrm{~mL}$ of Griess reagent (equal volumes of $1 \%$ sulfanilamide (in $5 \% \mathrm{H}_{3} \mathrm{PO}_{4}$ ) and $0.1 \% \mathrm{~N}$-alpha-naphthyl-ethylenediamine (in water)) was added; after $3 \mathrm{~min}$ of incubation, absorbance was measured at $546 \mathrm{~nm}$. Sodium nitrite was used as the positive control, and NO scavenging was calculated according to Eq. 1 . The scavenging activity was expressed as inhibition percentage. A blank (same mixture as described above with, however, $0.5 \mathrm{~mL}$ of distilled water replacing the extract) was used as control.

\subsection{Profiling and quantification of individual phenolic compounds by HPLC-DAD and LC-ESI-MS ${ }^{n}$}

RP-HPLC-DAD and RP-HPLC-ESI-MS ${ }^{n}$ analyses were carried out as previously described by Ferreira, Silva, Silva, and Nunes (2020) and Taghouti et al. (2018), respectively. Briefly, an Ultimate 3000 HPLC (Dionex, USA) equipped with an Ultimate 3000 pump, a WPS-3000 TSL Analyt auto-sampler, and an Ultimate 3000 column compartment coupled to a PDA-100 photodiode array detector were used for profiling and quantification. Chromatographic separation was performed using a C18 column (ACE $5 \mathrm{C} 18 ; 250 \mathrm{~mm} \times 4.6 \mathrm{~mm}$; particle size $5 \mu \mathrm{m}$ ). 
Chromeleon software (Version 7.1; Dionex, USA) was used for data acquisition, peak integration, and analysis. LC-ESI-MS ${ }^{n}$ analysis was carried out using a Thermo Scientific system consisting of a Finnigan Surveyor Plus auto-sampler, photodiode array detector and pump, and an LXQ Linear ion trap detector was used for LC-MS ${ }^{n}$ analysis. Chromatographic separation was performed with a Luna C18 (2) column (250 mm $\times 4.6 \mathrm{~mm}, 5 \mu \mathrm{m}$; Phenomenex (Aschaffenburg, Germany)), with temperature kept at $40{ }^{\circ} \mathrm{C}$. Electrospray ionization (ESI) was performed in the negative mode (capillary temperature: $350{ }^{\circ} \mathrm{C}$; capillary voltage: $-5 \mathrm{kV}$; spray voltage: $-4 \mathrm{kV}$ ). The RP-HPLC-DAD and RPHPLC-ESI-MS $^{n}$ program conditions, flow rate, eluents, injection volume and detection parameters were used exactly as described by Taghouti et al. (2018).

Individual phenolic compounds were identified based on UV-VIS spectra, retention time, and mass spectra compared to commercial standards and/or literature data. Calibration curves of available commercial standards were prepared for the quantification of individual phenolic compounds (Taghouti et al., 2018), or using the aglycones or standard compounds with structural similarity when commercial standards were not available. Apigenin-(6,8)-C-diglucoside and apigenin(?)-O-hexuronide were quantified as apigenin; Eriodyctiol-(?)-O-hexoside was quantified as eriodyctiol-(7)-O-hexoside; luteolin-(?)-O-hexoside and luteolin-(?)-O-hexorunide were quantified as luteolin; salvianolic acid A isomer was quantified as salvianolic acid A; salvianolic acids $\mathrm{K}$ and I were quantified as rosmarinic acid.

\subsection{Determination of oleanolic acid and ursolic acid in hydroethanolic extracts}

The identification and quantification of ursolic (UA) and oleanolic acids (OA) were performed in the HE extracts by RP-HPLC according to the method described previously by Martins-Gomes et al. (2018). Briefly, chromatographic separation was performed using a C18 column (ACE $5 \mathrm{C} 18 ; 250 \mathrm{~mm} \times 4.6 \mathrm{~mm}$; particle size $5 \mu \mathrm{m}$ ) using sodium phosphate buffer ( $30 \mathrm{mM}, \mathrm{pH}=3$ ) as solvent A and methanol as solvent $\mathrm{B}$. The volume injected was $50 \mu \mathrm{L}$, and the column temperature was kept at $40{ }^{\circ} \mathrm{C}$ during the run. Detection was performed at $210 \mathrm{~nm}$. $\mathrm{OA}$ and UA identification was performed by comparison with the UV-vis spectrum and retention time of OA and UA commercial standards, and quantification was performed by external calibration.

\subsection{In vitro cell viability assay}

Two human cell lines were used to evaluate the anti-proliferative/ cytotoxic activity of T. citriodorus and T. vulgaris extracts: Caco-2 (human colon adenocarcinoma cell line; CLS - Cell Lines Service, Eppelheim, Germany) and HepG2 (human hepatocellular carcinoma cell line; ATCC ${ }^{\circledR}$ Number: HB-8065TM, a gift from Prof. C. Palmeira CNC-UC, Portugal). Both cell lines were cultured in DMEM supplemented with $1 \mathrm{mM}$ L-glutamine, 10\% FBS and antibiotics $(100 \mathrm{U} / \mathrm{mL}$ penicillin and $100 \mu \mathrm{g} / \mathrm{mL}$ streptomycin). Cells were maintained at $37{ }^{\circ} \mathrm{C}$ in $5 \% \mathrm{CO}_{2} / 95 \%$ air with controlled humidity and handled as described by Severino et al. (2014). Stock solutions ( $10 \mathrm{mg} / \mathrm{mL})$ of $T$. citriodorus and T. vulgaris extracts were prepared in $\mathrm{PBS}$ for $\mathrm{AD}$ extracts and in PBS:DMSO (90:10) for HE extracts. The final concentration of DMSO in test solutions did not exceed $1 \%$.

Anti-proliferative/cytotoxic effects of extracts were evaluated using the Alamar Blue ${ }^{\circledast}$ assay (Andreani, Kiill, de Souza, Fangueiro, Fernandes, Doktorovova, et al., 2014). Briefly, cells suspended in culture media were seeded in 96-well plates (at $5 \times 10^{4}$ cells $/ \mathrm{mL} ; 100 \mu \mathrm{L}$ / well) and were allowed to adhere and stabilize for $48 \mathrm{~h}$. After this period, culture media was replaced by test solutions (100 $\mu \mathrm{L} /$ well), prepared by diluting the respective stock solutions in FBS-free culture medium (test solutions range 50-500 $\mu \mathrm{g} / \mathrm{mL}$ ). After exposure for $24 \mathrm{~h}$ or $48 \mathrm{~h}$, test solutions were removed and replaced by $100 \mu \mathrm{L} /$ well of Alamar Blue solution $(10 \%(\mathrm{v} / \mathrm{v})$, in FBS-free culture medium).
Absorbance was read after $5 \mathrm{~h}$ of incubation at $570 \mathrm{~nm}$ (reduced form; resorufin) and $620 \mathrm{~nm}$ (oxidized form; resazurin), using a Multiskan EX microplate reader (MTX Labsystems; Bradenton, Florida, USA). A control (non-exposed cells) was performed in each assay. Results are expressed as cell viability ( $\%$ of control), calculated as described by Andreani et al. (2014).

\subsection{Statistical analysis}

For each extraction method three individual extractions were performed, and the analyses were performed in triplicate for all assays. The $\mathrm{IC}_{50}$ values determined for the anti-proliferative activity were calculated as described by Silva et al. (2019). Significant differences between groups were assessed using the non-parametric Kruskal-Wallis method, followed by multiple pairwise comparisons using the Conover-Iman procedure $(\alpha=0.05)$. Correlations were evaluated using Pearson's coefficient (significant if $p<0.05$ ) and using the non-parametric Gamma correlation (significant if $p<0.05$ ). Graph construction and statistical analyses were performed using GraphPad Prism version 7 (GraphPad Software Inc, California, USA), Microsoft Office Excel Microsoft Corporation, Washington, USA) and Statistica 12.0 (Dell Software, Texas, USA) software.

\section{Results and discussion}

\subsection{Extract yield and chemical composition (Sum Parameters) of extracts}

In this study, two extraction methods were selected to obtain $T$. citriodorus and T. vulgaris extracts: 1) an exhaustive hydroethanolic (HE) extraction, previously shown to extract $99 \%$ of the total extractable compounds in the first three extractions (Martins-Gomes et al., 2018), was chosen as a method to obtain the vast majority of "free" phenolic compounds, allowing to study the full phenolic composition of the selected Thymus plants; 2) an aqueous decoction (AD) aiming to mimic the common procedure of beverage preparation for human consumption, as these plants are also used as herbal teas and condiments. For T. citriodorus, as expected, the exhaustive HE procedure resulted in higher yields than the one-step $\mathrm{AD}$ procedure $(\sim 14 \%$ vs. $\sim 9 \%(\mathrm{w} / \mathrm{w})$, for $\mathrm{HE}$ and $\mathrm{AD}$, respectively, Table 1$)$, but for T. vulgaris the yields between the $\mathrm{HE}$ and $\mathrm{AD}$ extracts were similar, although significantly higher for the $\mathrm{AD}$ extraction (Table 1 ). T. vulgaris yields were significantly higher than those obtained for T. citriodorus. Compared with yields (same extraction procedures) obtained for other Thymus species grown in the same location and harvested in the same year (2014) and time of year (October), i.e. T. pulegioides (Taghouti et al., 2018) and T. mastichina (Taghouti, Martins-Gomes, Schäfer, Santos, Bunzel, Nunes, et al., 2020) and obtained with the same extraction procedure harvested at the same phenological state (harvested in October), T. carnosus (Martins-Gomes et al., 2018), it can be observed (Supplementary material Fig. S.1) that T. citriodorus and T. mastichina presented lower HE extraction yields than T. vulgaris, T. carnosus, and T. pulegioides; the latter three species presented similar HE extraction yields. T. vulgaris presented the highest AD yield (Supplementary material Fig. S.2), and the AD yields followed the order T. vulgaris $>T$. carnosus $>$ T. pulegioides $>$ T. citriodorus $\sim T$. mastichina.

Although T. vulgaris showed significantly higher solid yields when compared to $T$. citriodorus, there were no significant differences in the contents of total phenolic compounds when the exhaustive HE extraction was used (Table 1). In fact, when compared to the other Thymus species analyzed (Supplementary material Fig. S.3) it can be observed that the TPC levels of T. citriodorus and T. vulgaris were not significantly different from that observed for T. mastichina (Taghouti et al., 2020). However, these three Thymus species contained significantly lower levels of TPC when compared to T. carnosus (Martins-Gomes et al., 2018) and T. pulegioides (Taghouti et al., 2018), with this last species containing the highest levels of TPC (Supplementary Material Fig. S.3). The 
Table 1

Extraction yields, chemical composition, and antioxidant activity of T. citriodorus (T. c.) and T. vulgaris (T. v.) extracts.

\begin{tabular}{|c|c|c|c|c|c|c|c|c|c|}
\hline & & \multicolumn{2}{|l|}{ T. citriodorus } & \multicolumn{2}{|l|}{ T. vulgaris } & \multicolumn{2}{|c|}{ Extraction method effect } & \multicolumn{2}{|c|}{ Plant species effect } \\
\hline & & HE & AD & HE & AD & T. $c$. & T. $v$. & HE & AD \\
\hline Extraction yield $(\%, w / w)$ & & \multicolumn{8}{|c|}{ Chemical composition } \\
\hline Total phenols & Ext. & $196.66 \pm 2.43$ & $165.14 \pm 5.43$ & $103.21 \pm 6.07$ & $84.16 \pm 6.40$ & * & * & * & * \\
\hline (mg caffeic acid equivalent/g) & D.P. & $27.66 \pm 4.57$ & $15.53 \pm 4.75$ & $25.12 \pm 1.48$ & $21.56 \pm 1.64$ & * & * & n.s. & n.s. \\
\hline Total flavonoids & Ext. & $255.93 \pm 9.02$ & $282.48 \pm 5.57$ & $196.17 \pm 8.66$ & $120.33 \pm 13.00$ & * & * & $*$ & * \\
\hline (mg catechin equivalent/g) & D.P. & $36.09 \pm 5.03$ & $26.51 \pm 5.41$ & $47.75 \pm 2.11$ & $30.86 \pm 3.34$ & $*$ & * & n.s. & n.s. \\
\hline Ortho-diphenols & Ext. & $176.70 \pm 8.65$ & $122.19 \pm 36.84$ & $96.16 \pm 2.31$ & $62.88 \pm 5.77$ & * & * & $*$ & $*$ \\
\hline (mg caffeic acid equivalent/g) & D.P. & \multicolumn{8}{|c|}{ Antioxidant activity } \\
\hline $\mathrm{ABTS}^{+}$ & Ext. & $1.52 \pm 0.21$ & $1.21 \pm 0.07$ & $0.92 \pm 0.03$ & $0.79 \pm 0.06$ & * & $*$ & $*$ & $*$ \\
\hline $\begin{array}{l}\text { (mmol Trolox equivalent) } \\
{ }^{\circ} \text { OH radicals }+ \text { EDTA }\end{array}$ & D.P. & $0.22 \pm 0.05$ & $0.11 \pm 0.03$ & $0.22 \pm 0.01$ & $0.20 \pm 0.01$ & * & n.s. & n.s. & * \\
\hline $\begin{array}{l}\text { (\% inhibition) } \\
\cdot \mathrm{OH} \text { radicals -EDTA }\end{array}$ & & & $37.97 \pm 1.12$ & - & $9.58 \pm 1.02$ & - & - & - & - \\
\hline $\begin{array}{l}\text { (\% inhibition) } \\
\text { NO }^{\circ} \text { radicals }\end{array}$ & & & $30.59 \pm 2.08$ & - & $20.71 \pm 4.15$ & - & - & - & - \\
\hline (\% inhibition, after $120 \mathrm{~min}$ ) & & \multicolumn{8}{|c|}{ Anti-proliferative activity $\left(I C_{50}, \mu \mathrm{g} / \mathrm{mL}\right)$} \\
\hline Caco- 2 cells & & & & & & & & & \\
\hline & $24 \mathrm{~h}$ & $128.2 \pm 5.75$ & $223.70 \pm 8.38$ & $>500$ & $>500$ & * & n.s. & * & * \\
\hline & $48 \mathrm{~h}$ & $114.6 \pm 4.38$ & $159.40 \pm 16.85$ & $442.45 \pm 53.25$ & $376.8 \pm 23.20$ & * & n.s & * & * \\
\hline HepG2 Cells & $24 \mathrm{~h}$ & $\begin{array}{l}>500 \\
>500\end{array}$ & $\begin{array}{l}>500 \\
>500\end{array}$ & $495.05 \pm 11.55$ & $\begin{array}{l}>500 \\
>500\end{array}$ & n.s & $\begin{array}{l}\text { n.s. } \\
*\end{array}$ & n.s. & n.s. \\
\hline
\end{tabular}

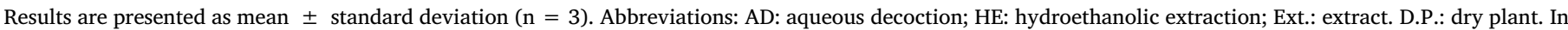

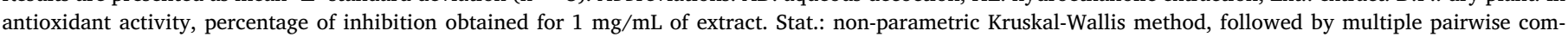
parisons using the Conover-Iman procedure if $(p<0.05)$ were denoted as $(*)$.

(unspecific) sum parameter TPC includes flavonoids, too, which have been measured here as TFC. Levels of TFC obtained by exhaustive HE extraction were not significantly different between $T$. citriodorus and $T$. vulgaris (Table 1). Contrarily to the TPC levels, the TFC levels did not statistically differ among $T$. pulegioides, T. carnosus, and T. vulgaris. Generally, T. mastichina presented the lowest TFC value, followed by $T$. citriodorus (Supplementary Material Fig. S.4). Phenolic compounds containing ortho-diphenol structural units were measured as ODP. Different from what was seen for the TFC levels, ODP levels in the different Thymus species obtained by exhaustive HE extraction (Supplementary Fig. S.5) followed the same trend as observed for the TPC levels, with $T$. pulegioids presenting the highest ODP levels, whereas the other Thymus species did not show significantly different ODP values.

The TPC compositions of the various AD extracts did not follow the same trend as observed for the exhaustive HE extracts, as significantly different TPC extraction yields were analyzed for T. citriodorus and T. vulgaris (Table 1). However, by using AD extraction $86 \%$ of the plant TPC were extracted from $T$. vulgaris, whereas only $56 \%$ of the plant TPC were extracted from T. citriodorus (Table 1). Different TPC extraction yields using either AD or HE were also observed for the other Thymus species (Supplementary Material Fig.s S.3 and S.6.). For T. carnosus, in line with that observed for T. vulgaris, the AD extraction was also able to extract $85 \%$ of the TPC present in the plant, while for T. mastichina and T. pulegioides the $\mathrm{AD}$ extraction was only able to extract $51 \%$ and $47 \%$, respectively, of the TPC of the plants. These results show that plant TPC is not directly related with the TPC of the $\mathrm{AD}$, and this may be due to the structural features of the phenolic compounds present in each plant or to different structural and morphological features of each plant and their respective cells. The AD obtained from T. carnosus contained the highest level of TPC among all Thymus species studied (Supplementary Material Fig. S.6), whereas the T. mastichina AD contained the lowest TPC level (Supplementary material Fig. S.6.). The ODP levels of the AD extracts from the different Thymus species were similar, with the exception of the AD from T. mastichina, which contained a significantly lower ODP level (Supplementary material Fig. S.7). Considering the flavonoids extracted by using the AD extraction, TFC contents from $T$. pulegioides were higher than those from the other Thymus species with the exception of $T$. vulgaris, although the TFC level of $T$. vulgaris did not statistically differ from $T$. carnosus and T. citriodorus (Supplementary Material Fig. S.8). The lowest TFC content was analyzed in the $T$. mastichina AD extract. This is the first work describing the comparative composition of extracts obtained using the same extraction procedures from different Thymus species grown in this specific location in Portugal for the 2014 harvesting year (T. citriodorus, T. vulgaris, T. mastichina and T. pulegioides) and additionally $T$. carnosus extracts obtained with the same extraction procedure at the same phenological stage, therefore corresponding to specific edaphoclimatic conditions, and hence further work is need to validate these results for other growing locations and harvest years.

\subsection{Phenolic compound profiles in aqueous decoction and hydroethanolic extracts}

In order to understand whether the extraction and compositional variations, between T. vulgaris and T. citriodorus (and the other Thymus species), described in section 3.1., are reflected by their phenolic profiles and their individual phenolic compounds, the phenolic composition of T. citriodorus and T. vulgaris was determined by HPLC-DAD and HPLC-MS $^{n}$. The phenolic profiles as well as the individual phenolic compounds and their concentrations in the HE extracts from T. citriodorus and T. vulgaris are shown in Fig. 1 and in Table 2. Table 2 also shows the phenolic compounds and their concentrations in AD extracts of both Thymus species. The relative amount of each phenolic compound present in HE and AD extracts determined by HPLC-DAD is consistent with the results obtained by the colorimetric methods discussed above for the TPC, TFC and ODP (Table 1). For both Thymus species and both extraction methods, rosmarinic acid was the most abundant phenolic compound (Table 2). Rosmarinic acid represented $54 \%$ and $66 \%$ of the total phenolic compounds (sum of individual phenolic compounds) extracted by the HE for T. citriodorus and T vulgaris, respectively. The amount of rosmarinic acid in both T. citriodorus and T. vulgaris plants was significantly lower than in T. pulegioides 

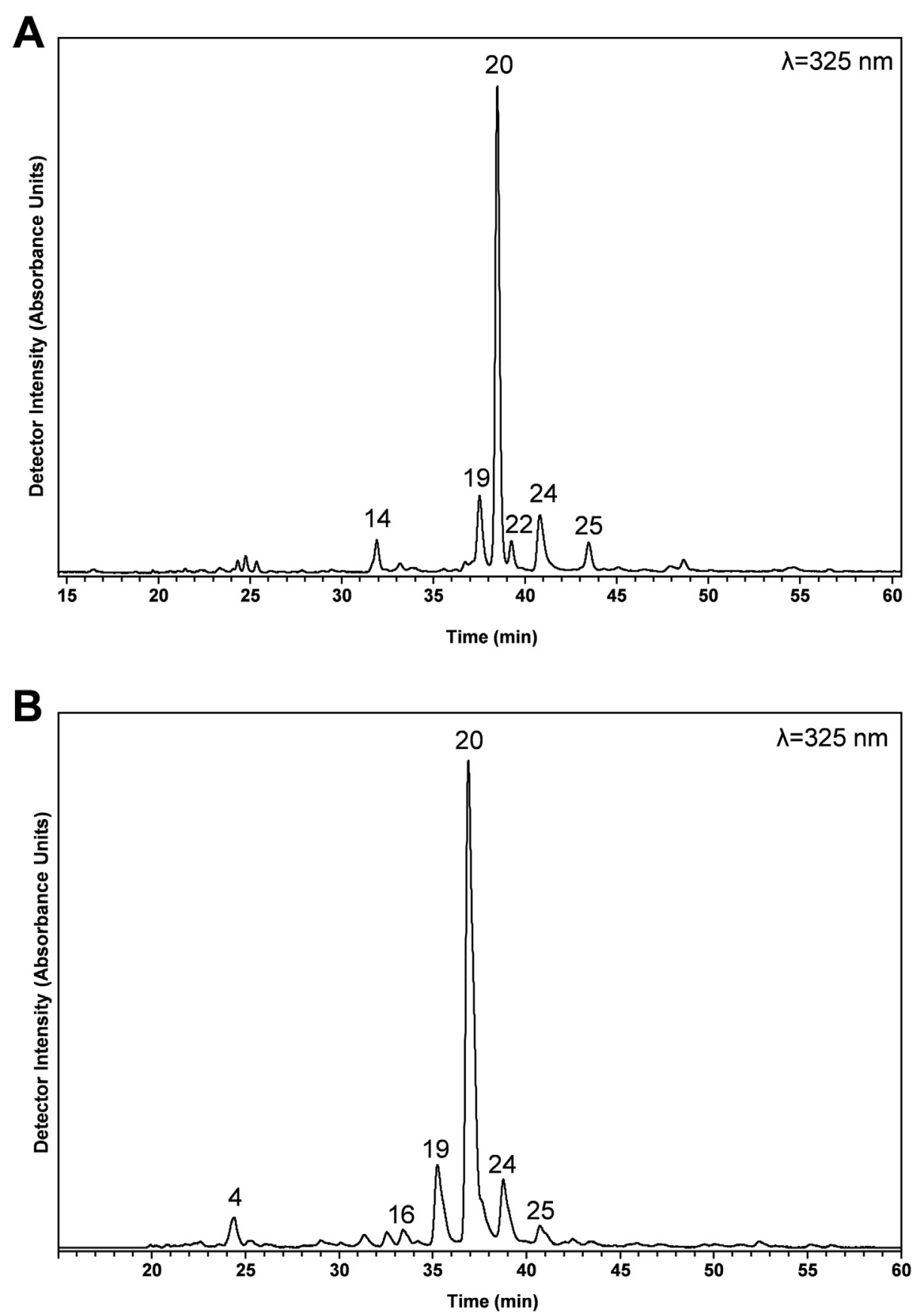

Fig. 1. Phenolic profiles of hydroethanolic (HE) extracts from T. citriodorus (A) and T. vulgaris (B). For peak identification please refer to Table 2 .

plants (Taghouti et al., 2018) but higher than in T. carnosus plants (Martins-Gomes et al., 2018) and T. mastichina (Taghouti et al., 2020). The share of rosmarinic acid in the total phenolic content (sum of individual phenolics, HE extracts) in T. vulgaris (66\%) and T. citriodorus (54\%) is higher than in T. pulegioides (35\%), T. mastichina (34\%) and T. carnosus $(20 \%)$. Although other phenolic compounds were quantified in the various extracts, rosmarinic acid was the only phenolic compound present in quantifiable amounts across all five Thymus species. Other phenolic compounds that were present in quantifiable amounts in some Thymus species extracts were detected by HPLC-MS (Table 2) in the other extracts, too, but the signal-to-noise ratios in the UV-detected chromatograms did not allow for the quantification. Phenolic compounds that were detected in all Thymus species but could not be quantified in all species were eriodictyol-hexoside (not quantified in $T$. mastichina), luteolin-hexoside (not quantified in T. citriodorus), salvianolic acid I (not quantified in T. carnosus) and salvainolic acid $\mathrm{K}$ (not quantified in T. pulegioides). T. citriodorus and T. vulgaris did not present quantifiable amounts of eriodictyol-di-hexoside, eriodictoyolhexorunide and naringenin-hexoside (only quantified in T. pulegioides), quercetin-hexoside, salvianolic acid B/E isomer 2 and chrysoeriolhexuronide (only quantified in T. mastichina) and luteolin-pentosidehexoside and salvianolic acid A (only quantified in T. carnosus). On the other hand the salvainolic acid A isomer, previously described in $T$. carnosus and T. mastichina by our research group, is also present in quantifiable amount in $T$. citriodorus but not in T. vulgaris.

Concerning the relative amount of total salvianolic acids and rosmarinic acid to the total flavonoids present in each Thymus plant, T. carnosus presented the highest ratio (15.2) followed by T. vulgaris (5.6), T. citriodorus (3.0), T. mastichina (2.6), and T. pulegioides (0.51). T. citriodorus that is a hybrid between $T$. pulegioides and $T$ vulgaris presents a 
Table 2

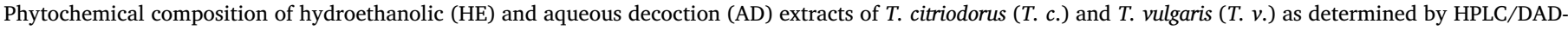
ESI/MS.

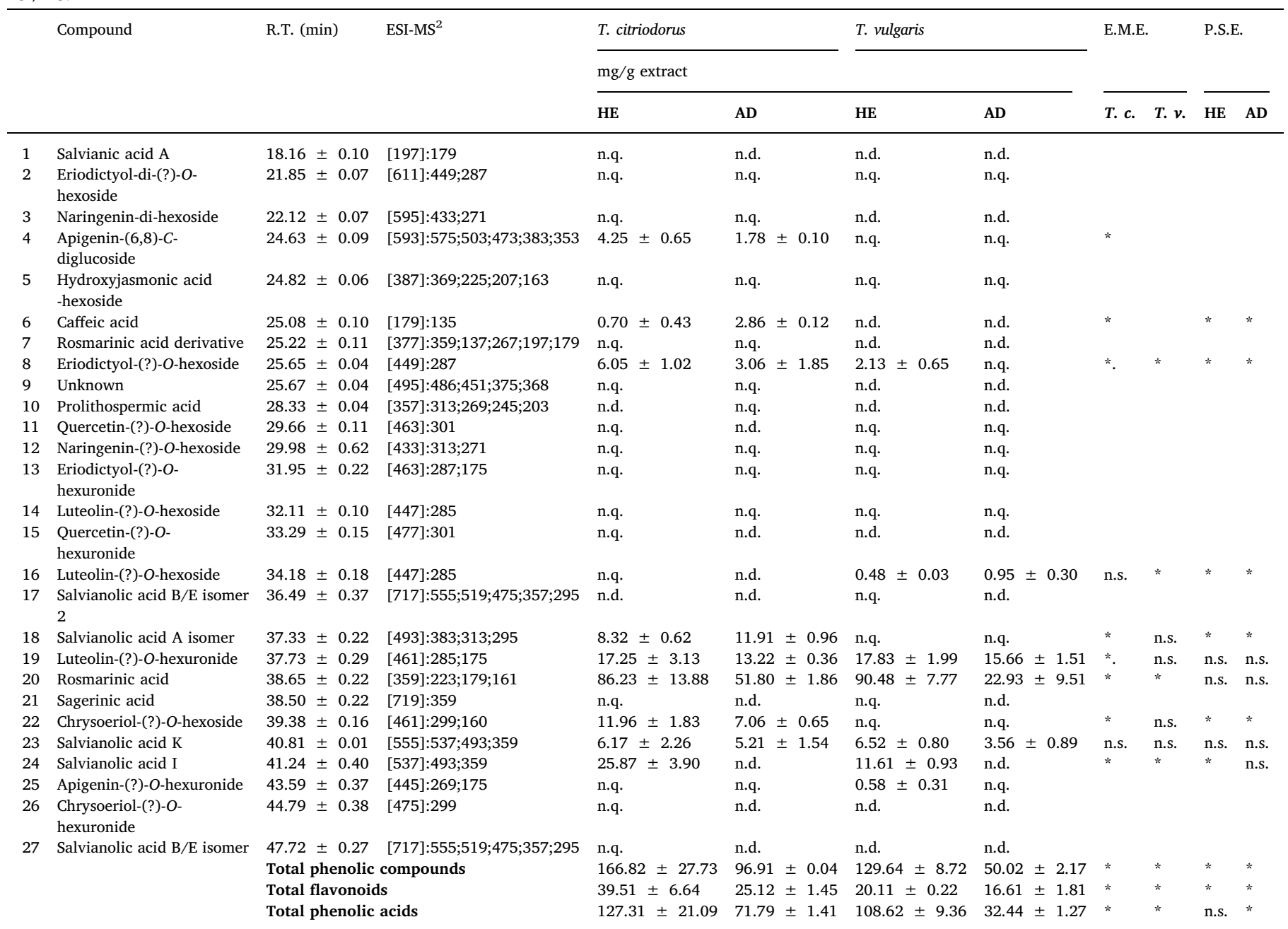

Abbreviations: RT: retention time; ESI-MS ${ }^{2}$ : Fragment ions obtained after fragmentation of the pseudo-molecular ion $[\mathrm{M}]^{-}$; n.q.: not quantified; n.d.: not detected; E.M.E.: extraction method effect; P.S.E.: plant species effect. Stat.: non-parametric Kruskal-Wallis method, followed by multiple pairwise comparisons using the Conover-Iman procedure if $(p<0.05)$ were denoted as (*). Results are presented as content in $\mathrm{mg}$ / gram as mean \pm standard deviation, $\mathrm{n}=3$.

chemical composition much more comparable to T. vulgaris than to $T$. pulegioides, concerning both the profile of phenolic compounds and their amounts. In fact, using both the chemical composition of the five Thymus plants obtained by exhaustive HE extraction as chemical descriptors, and cluster analysis as a pattern recognition method, the formation of three distinct clusters can be observed: the cluster on the left comprises the T. carnosus sample, the middle cluster is only composed of T. pulegioides, and the third cluster at the right contains $T$. mastichina, T. citriodorus, and T. vulgaris (Fig. 2A and C).

A logarithmic relation between the amount of total phenolic compounds extracted by $\mathrm{AD}$ extraction and the amount of total phenolic compounds present in the plant (exhaustive HE extraction) was observed (Fig. 2B). A logarithmic relation was also found for the amount of both rosmarinic acid and salvianolic acid $\mathrm{K}$ being either extracted with $\mathrm{AD}$ or HE. Therefore, this logarithmic relation between the amounts of total phenolic compounds and selected phenolic compounds extracted with $\mathrm{AD}$ or $\mathrm{HE}$ confirms the differences in extraction yields as observed for the different Thymus species discussed previously. However, the chemical nature of the individual compounds strongly affects the AD extractability, too. For example, salvianolic acid I, although present in Thymus plants with the exception of T. carnosus, was not extracted in quantifiable amounts by using AD (Table 2). Nevertheless, although there are differences among the AD and HE extract compositions, concerning the phenolic compounds present and their contents for each Thymus, cluster analysis of the AD and HE (Supplementary Material Fig. S.9) extracts concerning their phenolic composition show that the AD extracts from each Thymus are still more similar to the HE extracts obtained from the same Thymus, reflecting the impact of Thymus plants composition of the AD extract obtained (Supplementary Material Fig. S.10).

\subsection{Oleanolic acid and ursolic acid contents}

Oleanolic (OA) and ursolic (UA) acids are two triterpenes that are commonly described as being present in the alcoholic extracts from various Thymus species, for example, from $T$. serpyllum (3.7 and $13.9 \mathrm{mg} / \mathrm{g}$ dry plant, for OA and UA, respectively (Janicsák, Veres, Zoltán Kakasy, \& Máthé, 2006), T. carnosus (9.9 and $18.7 \mathrm{mg} / \mathrm{g}$ dry plant, for OA and UA respectively (Martins-Gomes et al., 2018), and T. pulegioides $(0.34$ and $0.80 \mathrm{mg} / \mathrm{g}$ dry plant, for OA and UA respectively (Taghouti et al., 2018). However, these triterpenes were not detected in the HE extracts from T. vulgaris and T. citriodorus (Table 2), just as previously observed for T. mastichina (Taghouti et al., 2020). Nevertheless, Janicsák et al. (2016) reported that T. vulgaris and T. citriodorus 
A

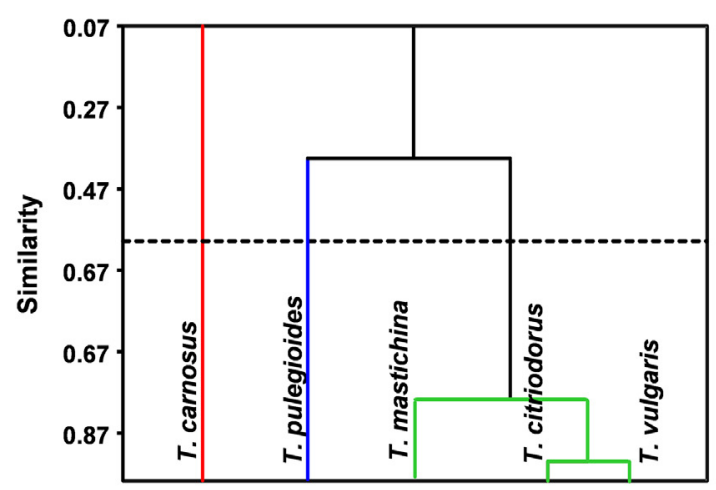

C
B

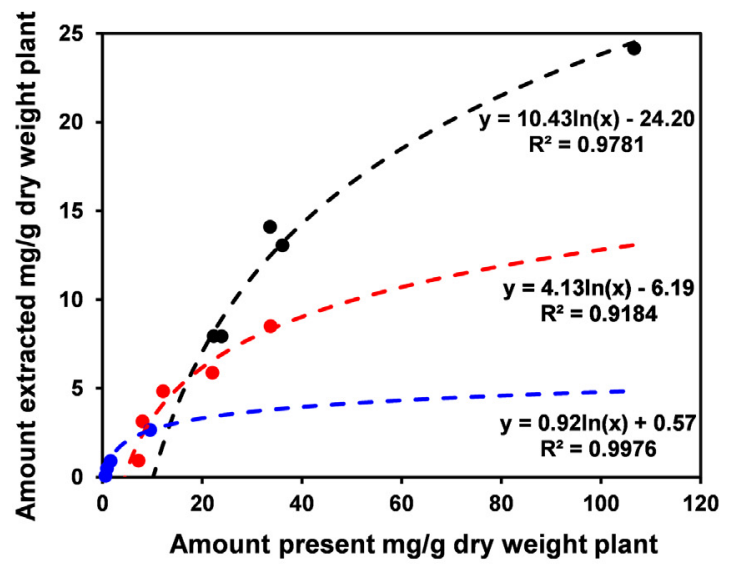

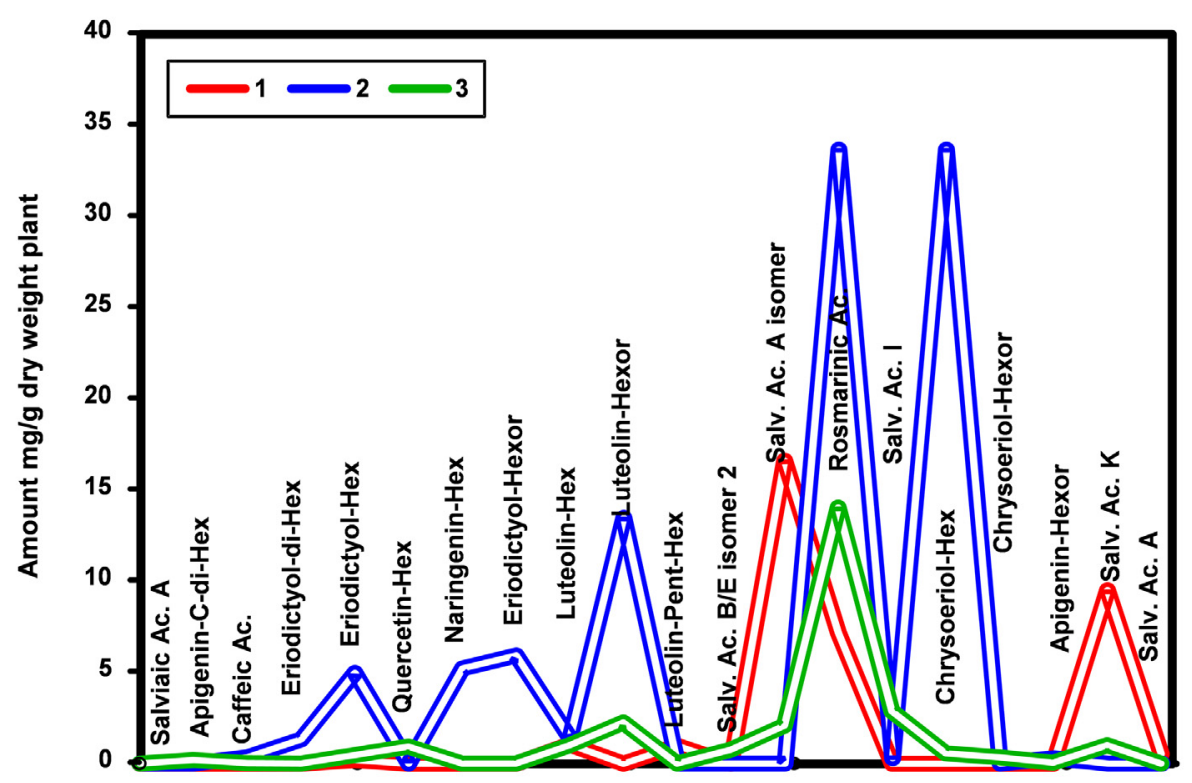

Phenolic Compound

Fig. 2. (A) Dendogram of cluster analysis based on the phenolic composition of hydroethanolic (HE) extracts. (B) Relation between the amount of total phenolic compounds $(\bullet)$, rosmarinic acid $(\bullet)$ and salvianolic acid K $(\bullet)$ extracted by aqueous decoction (AD) (y-axis) and by HE extraction (x-axis) of Thymus plants. (C) Average levels of phenolic compounds present in each cluster.

(collected in Hungary; July 1999) extracts, obtained by using Soxhlet extraction with methanol as solvent for $6 \mathrm{~h}$, contained measurable amounts of OA (1.7 and $2.6 \mathrm{mg} / \mathrm{g}$ dry weight) and of UA (5.2 and $6.4 \mathrm{mg} / \mathrm{g}$ dry weight), respectively to $T$. vulgaris and T. citriodorus. These differences may reflect a different phenological state of the plant, the effect of location and climate on chemical composition of plants, and may also result from a different extraction method and solvent.

\subsection{In vitro antioxidant activity}

The extracts of $T$. citriodorus and T. vulgaris showed a significant scavenging activity of ABTS radical cations (Table 1). As expected, significantly higher scavenging activity values were obtained for the HE extracts ( $\sim 1.52$ and $0.92 \mathrm{mmol}$ Trolox eq./g extract, respectively; Table 1$)$ as compared to the $\mathrm{AD}$ extracts $(\sim 1.21$ and $0.79 \mathrm{mmol}$ Trolox eq./g extract, respectively, Table 1). The values expressed as Trolox eq./g dry plant (Table 1) were lower than those found by Taghouti et al. (2018)) for HE and AD extracts of T. pulegioides ( 0.15 and $0.34 \mathrm{mmol}$ Trolox eq./g dry plant, respectively), in the same range of those values found for the extracts of $T$. carnosus $(0.14$ and $0.21 \mathrm{mmol}$ Trolox eq. $/ \mathrm{g}$ dry plant, respectively) (Martins-Gomes et al., 2018) and higher than those observed for T. mastichina ( 0.08 and $0.20 \mathrm{mmol}$ Trolox eq./g dry plant, respectively) (Taghouti et al., 2020). Although a significant correlation between the extracts TPC $(r=0.827, p<0.00316)$, TFC $(\mathrm{r}=0.798, \mathrm{p}<0.005663)$ and ODP $(\mathrm{p}<0.910, \mathrm{p}<0.000257)$ and their Trolox equivalent antioxidant capacity (TEAC) was observed, a more detailed analysis of the impact of the individual phenolic compounds present in the extracts on the antioxidant activity showed that rosmarinic acid mostly affects the antioxidant activity presented by the extract $(r=0.874, p<0.000945)$. This is partially explained by the fact that it is the major phenolic compound in most extracts as discussed above. Nevertheless, the contents of other phenolic compounds also showed significant correlations with the observed TEAC values, e.g. eriodictyol-glucoside ( $\mathrm{r}=0.759, \mathrm{p}<0.0109)$, luteolin-hexuronide ( $r=0.734, p<0.0157)$, and chrysoeriol-hexoside $(r=0.771$, $\mathrm{p}<0.00903)$. In fact, a significant correlation $(\mathrm{r}=0.878$, $\mathrm{p}<0.000834$ ) between the plants antioxidant activity with their total phenolic compounds extracted by the two extraction methods, obtained by the sum of the individual phenolic compounds, was observed.

Results from the hydroxyl radical ( $\left.{ }^{\circ} \mathrm{OH}\right)$ scavenging assays 
demonstrated that $\mathrm{AD}$ extracts from $T$. citriodorus inhibit hydroxyl radicals more strongly than $\mathrm{AD}$ extracts from $T$. vulgaris. This was found in the absence and in the presence of EDTA in the test system, namely the T. citriodorus ${ }^{\circ} \mathrm{OH}$ scavenging activity was about 1.5 -fold (-EDTA) and 4.2-fold (+EDTA) higher as compared to T. vulgaris (Table 1). However, the activity of the $T$. citriodorus extracts (Table 1 ) was lower than the activity of a methanolic extract of T. dacicus (Petrović et al., 2017), which produced $50 \%$ of the radical scavenging at $18.85 \mu \mathrm{g} / \mathrm{mL}$. However, the inhibition percentage of T. citriodorus extracts was comparable to $\mathrm{AD}$ extracts of T. carnosus (Martins-Gomes et al., 2018) and to $\mathrm{AD}$ extracts of T. pulegioides (Taghouti et al., 2018) and T. mastichina (Taghouti et al., 2020).

Concerning the scavenging of NO radical, T. vulgaris extracts showed a higher ( $\sim 1.4$-fold) scavenging activity when compared to $T$. citriodorus (41\%; Table 1). Similar values of NO radical scavenging activity were observed for AD extracts from T. carnosus (40\%) (MartinsGomes et al., 2018) and for AD extracts from T. pulegioides (35.76\%) (Taghouti et al., 2018) and T. mastichina (39\%) (Taghouti et al., 2020).

\subsection{Anti-Proliferative effect of T. Citriodorus and T. Vulgaris extracts}

In order to evaluate the anti-proliferative effect of $\mathrm{AD}$ and $\mathrm{HE}$ extracts from T. citriodorus and T. vulgaris, we used the Alamar Blue (AB) reduction assay and two cell lines, HepG2 and Caco-2. Cells were exposed to different concentrations of $T$. citriodorus and $T$. vulgaris extracts $(50,100,200$, and $500 \mu \mathrm{g} / \mathrm{mL}$ ) for $24 \mathrm{~h}$ or $48 \mathrm{~h}$, and results were compared with those obtained from control cells (non-exposed cells). The effect of both extracts was more pronounced on Caco-2 cells (Fig. 3) than on HepG2 cells (Supplementary Material Fig. S.11). HE extracts presented a higher anti-proliferative activity/cytotoxicity on Caco-2 cells than the AD extracts (Fig. 3), which correlates with their concentration of phenolic compounds (Table 2; TPC HE/AD: 1.7 and 2.6 in T. citriodorus and T. vulgaris, respectively). On Caco-2 cells, the half-maximal inhibitory concentration $\left(\mathrm{IC}_{50}\right.$ ) of $\mathrm{HE}$ extracts, at $24 \mathrm{~h}$ exposure, was statistically significant lower than the $\mathrm{IC}_{50}$ values obtained for the AD extracts of T. citriodorus (HE: $128.2 \pm 5.75 \mu \mathrm{g} / \mathrm{mL}$; AD: $223.70 \pm 8.38 \mu \mathrm{g} / \mathrm{mL}$ ) and T. vulgaris ( $\mathrm{IC}_{50}>500 \mu \mathrm{g} / \mathrm{mL}$, both extracts). The same trend was observed after $48 \mathrm{~h}$ of exposure with the effect of exposure time being evident, as the $\mathrm{IC}_{50}$ values were lowered when compared to $24 \mathrm{~h}$ of exposure (Table 1 ). Caco-2 cells were more sensitive to T. citriodorus and T. vulgaris extracts than HepG2 cells as indicated by statistically significant lower $\mathrm{IC}_{50}$ values after $24 \mathrm{~h}$ or $48 \mathrm{~h}$ of exposure (Table 1 ) for both extracts. The $\mathrm{IC}_{50}$ values obtained for the treatment of Caco-2 cells with $\mathrm{HE}$ and $\mathrm{AD}$ extracts from $T$. vulgaris were higher than those observed for the treatment with $T$. citriodorus extracts (Table 1) and also higher than those reported for the HE and AD extracts from T. carnosus (Martins-Gomes et al., 2019), T. pulegioides (Taghouti et al., 2018), and T. mastichina (Taghouti et al., 2020). On the other hand, for the same cell line, $\mathrm{IC}_{50}$ values obtained for $T$. citriodorus HE extracts (Table 1) were higher than those reported for T. carnosus (Martins-Gomes et al., 2019) and T. mastichina (Taghouti et al., 2020) HE extracts, and similar to that reported from T. pulegioides (Taghouti et al., 2018). Concerning T. citriodorus AD extracts, the $\mathrm{IC}_{50}$ values obtained on Caco-2 cells ( $24 \mathrm{~h}: 224 \mu \mathrm{g} / \mathrm{mL} ; 48 \mathrm{~h}: 159 \mu \mathrm{g} / \mathrm{mL}$ ) are lower than those obtained for $T$. carnosus AD extracts ( $24 \mathrm{~h}: 510 \mu \mathrm{g} / \mathrm{mL} ; 48 \mathrm{~h}$ : $203 \mu \mathrm{g} / \mathrm{mL}$ (Martins-Gomes et al., 2019)), but higher than those obtained for T. pulegioides ( $24 \mathrm{~h}$ : $138 \mu \mathrm{g} / \mathrm{mL} ; 48 \mathrm{~h}: 82 \mu \mathrm{g} / \mathrm{mL}$, (Taghouti et al., 2018)) and T. mastichina (24 h: $221 \mu \mathrm{g} / \mathrm{mL} ; 48 \mathrm{~h}: 96 \mu \mathrm{g} / \mathrm{mL}$ (Taghouti et al., 2020) AD extracts.

Concerning HepG2 cells, at both exposure times, the $\mathrm{IC}_{50}$ values obtained for T. citriodorus $\mathrm{AD}$ and $\mathrm{HE}$ extracts were higher than the experimental concentrations tested in this work $(>500 \mu \mathrm{g} / \mathrm{mL}$; Table 1), denoting very low cytotoxicity for this cell line. These values are higher than that observed for the HE extracts from T. vulgaris (24 h: $495 \mu \mathrm{g} / \mathrm{mL} ; 48 \mathrm{~h}: 254 \mu \mathrm{g} / \mathrm{mL}$ (Table 1 ). The $\mathrm{IC}_{50}$ values of $T$. vulgaris $\mathrm{AD}$ extracts on HepG2 cells, after $48 \mathrm{~h}$ exposure (> $500 \mu \mathrm{g} / \mathrm{mL}$ ), higher than those obtained for $T$. carnosus $(478 \mu \mathrm{g} / \mathrm{mL}$ (Martins-Gomes et al., 2019) and T. mastichina (285 $\mu \mathrm{g} / \mathrm{mL}$ (Taghouti et al., 2020), indicate
A

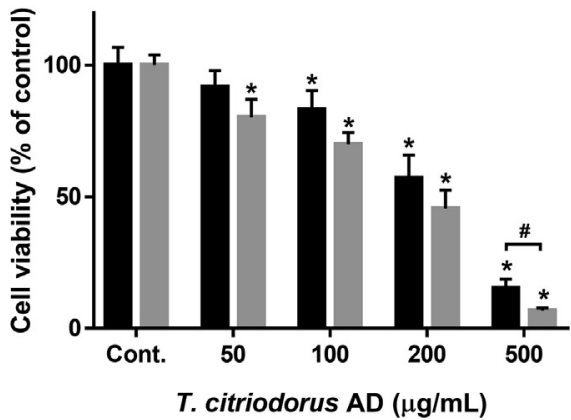

B

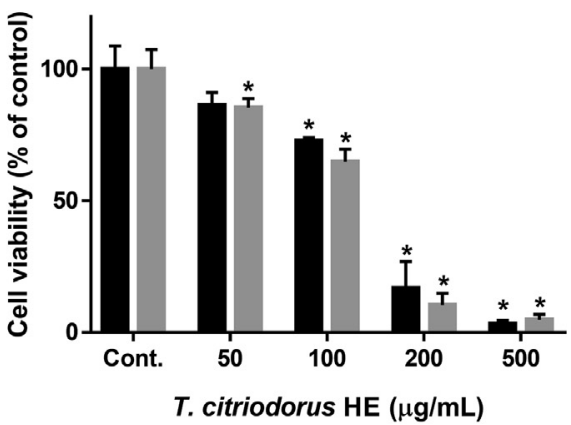

C
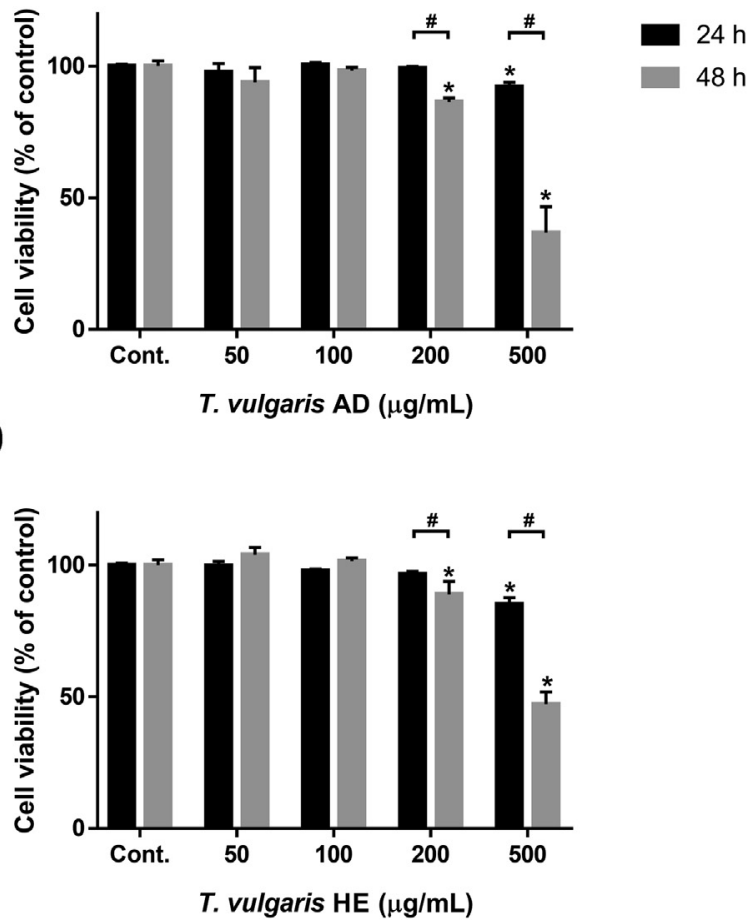

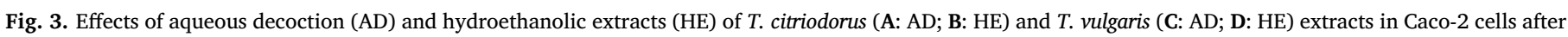

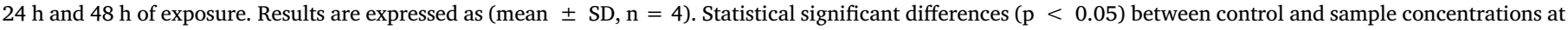
respective incubation time are denoted by *, and between concentration periods at same concentration are denoted by $\#$. 
Table 3

Association between the phenolic compounds present in aqueous decoction and hydroethanolic extracts from the five Thymus species and the $\mathrm{IC}_{50}$ values observed for Caco-2 and HepG2 cell lines exposed for 24 and 48 h to the extracts, using the Gamma non-parametric correlation .

\begin{tabular}{lllll}
\hline & Caco-2 & \multicolumn{3}{c}{ HepG2 } \\
\cline { 2 - 5 } & $\mathbf{2 4} \mathbf{~ h}$ & $\mathbf{4 8 ~ h}$ & $\mathbf{2 4} \mathbf{~ h}$ & $\mathbf{4 8 ~ h}$ \\
\hline Total phenolic compounds & & & & \\
Total salvianolic and rosmarinic acids & -0.511 & -0.467 & -0.543 & \\
Quercetin-(?)-O-hexoside & & -0.467 & -0.771 & -0.571 \\
Luteolin-(?)-O-pentoside-hexoside & & -0.647 & -0.538 & -0.647 \\
Salvianolic acid B/E isomer 2 & & -0.647 & -0.538 & -0.647 \\
Salvianolic acid A isomer & & & & -0.538 \\
Salvianolic acid I & & & -0.478 & \\
Chrysoeriol-(?)-O-hexuronide & & -0.647 & -0.538 & -0.647 \\
Oleanolic acid & -0.647 & -0.647 & -0.692 & -0.647 \\
Ursolic acid & -0.647 & -0.647 & -0.692 & -0.647 \\
\hline
\end{tabular}

a sum of individual phenolic compounds determined by HPLC.

low cytotoxicity on this cell line.

In order to explore the possible associations between the chemical composition of the extracts of the five Thymus species obtained by the two extraction methods (HE and $\mathrm{AD}$ ) and the observed ant-proliferative/cytotoxic activity of these extracts against Caco-2 and HepG2 cell lines for the two exposure times, evaluated by their $\mathrm{IC}_{50}$ values, a non-parametric gamma correlation was performed. As can be observed in Table 3, there is a significant association between the total phenolic compounds (obtained by summing up the individual phenolic compounds) present in the extracts and the $\mathrm{IC}_{50}$ values of the extracts studied for both cell lines, although, in case of the HepG2 cell line, this is only true for the $\mathrm{IC}_{50}$ values determined after $24 \mathrm{~h}$. On the other hand, the Total Salvianolic Acids content of the extracts also showed a significant association to the observed $\mathrm{IC}_{50}$ values for both cell lines and exposure times. Oleanolic and ursolic acids also showed a significant association between their relative content and the observed $\mathrm{IC}_{50}$ values for both cell lines and exposure times. Among the individual phenolic compounds in the extracts, quercetin-hexoside, salvianolic acid $\mathrm{B} / \mathrm{E}$ isomer 2, and chrysoeriol-hexuronide show a significant association to the $\mathrm{IC}_{50}$ values obtained for the Caco- 2 cell line after $48 \mathrm{~h}$ exposure (but not for $24 \mathrm{~h}$ of exposure) and for the HepG2 cell line for both times of exposure. These results support the importance of the salvianolic acid composition of the Thymus extracts obtained for the different Thymus species and their anti-proliferative/cytotoxic activity, although the flavonoids present can also have a significant influence on the antiproliferative/cytotoxicity of the Thymus extracts.

Wang, Wu, Tao, Liu, and El-Nezami (2011) observed that salvianolic acid $\mathrm{B}$ induced a time- and dose-dependent reduction on HepG2 cell proliferation. Salvianolic acid B, at the highest tested concentration $(250 \mu \mathrm{M})$, induced a reduction on cell proliferation of $75 \%$ and $80 \%$, after 24 and $48 \mathrm{~h}$ of exposure, respectively (Wang et al., 2011). In another study, salvianolic acid B inhibited the growth of several head and neck squamous carcinoma cell lines (JHU-022 and JHU-013 cells), with $\mathrm{IC}_{50}$ values of $18 \mu \mathrm{M}$ and $50 \mu \mathrm{M}$, respectively (Hao, Xie, Korotcov, Zhou, Pang, Shan, et al., 2009). Also, salvianolic acid B at a concentration of $125 \mu \mathrm{M}$ reduced the cell viability of different human cancer cell lines, namely, liver cell lines, Huh-7 and SK-HEP-1, to $45 \%$ and to $25 \%$ of the control (Hao et al., 2009). Salvianolic acids A and B have been reported as good candidates against several types of cancer as these molecules target several cell mechanisms involved in apoptosis, cell cycle regulation, and inflammation (Hao et al., 2009; Qin, Rasul, Sarfraz, Sarfraz, Hussain, Anwar, et al., 2019). This is because salvianolic acids act through mechanisms that modulate various signaling pathways (e.g., mitogen activated protein kinase (MAPK), phosphoinositide-3-kinase-protein kinase B/Akt (PI3K/PKB/Akt), nuclear factor kappa B (NF-kB), mammalian target of rapamycin (mTOR) pathways), which are often deregulated in cancer cells and are usually associated with drug resistance (Qin et al., 2019). Nevertheless, the nature of salvianolic acid derivatives present in the extracts can also influence the anti-proliferative activity, as shown here by the significant associations of some individual salvanolic acids and the anti-proliferative/cytotoxic activity of the extracts obtained from the different Thymus species (Table 3).

\section{Conclusions}

This is the first work describing the detailed phenolic composition of exhaustive hydroethanolic (HE) and aqueous decoction (AD) extracts of $T$. vulgaris and $T$. citriodorus, grown under the same conditions and collected at same phenological stage. The phenolic composition of each extract was correlated with its observed in vitro bioactivities. Among other common phenolic compounds normally present in Thymus species, salvianolic acids $\mathrm{K}$, I and A isomer were identified. Extracts of $T$. vulgaris and T. citriodorus showed a significant scavenging activity of ABTS $^{*},{ }^{\circ} \mathrm{OH}$, and NO'. The HE extract from T. citriodorus showed the best anti-proliferative activity against Caco-2 cells while T. vulgaris extracts showed low and very-low cytotoxicity against Caco-2 and HepG2 cells, respectively. T. vulgaris and T. citriodorus polyphenol composition and bioactivities were compared to those of T. pulegioides, and T. mastichina, grown under the same edaphoclimatic conditions. Cluster analysis supports that $T$. citriodorus polyphenol composition is more similar to T. vulgaris than to T. pulegioides. A significant association between the total phenolic compounds, obtained by summing up the individual phenolic compounds, and the individual compounds present in the extracts, namely salvianolic acid B/E isomer 2, A isomer and I as well as total salvianolic acids and rosmarinic acid, with the anti-proliferative/cytotoxicity of both cell lines was observed when considered the results obtained from the five Thymus species. These results support the importance of the levels of salvianolic acids in Thymus extracts and their anti-proliferative/cytotoxic activity.

\section{Funding}

This work was supported by INTERACT project-"Integrative Research in Environment, Agro-Chains and Technology", no. NORTE01-0145-FEDER-000017, Fund (ERDF) through NORTE-2020. By funds from the Portuguese Science and Technology Foundation (FCT), Ministry of Science and Education (FCT/MEC) through national funds, and co-financed by FEDER, under the projects UIDB/04033/2020 (CITAB) and UIDB/00616/2020 and UIDP/00616/2020 (CQ-VR). The authors would like to thank the grants from FCT: (PD/BD/52563/2014) to M.T. and (SFRH/BD/145855/2019) to C.M.G, and from INTERACT project (BI/UTAD/INTERACT/ISAC/203/2016) to L.F. The author also would like to thank to the FEDER, Interreg España-Portugal Programme, under the framework of the Project 0377_IBERPHENOL_6_E.

\section{CRediT authorship contribution statement}

Meriem Taghouti: Investigation, Data curation, Formal analysis, Writing - original draft. Carlos Martins-Gomes: Investigation, Writing - original draft, Data curation, Formal analysis, Writing - review \& editing. Luís M. Félix: Investigation, Data curation, Formal analysis, Writing - review \& editing. Judith Schäfer: Investigation, Data curation, Formal analysis, Writing - review \& editing. Joà A. Santos: Supervision, Writing - review \& editing. Mirko Bunzel: Methodology, Resources, Investigation, Writing - review \& editing. Fernando M. Nunes: Conceptualization, Project administration, Methodology, Resources, Supervision, Formal analysis, Data curation, Visualization, Writing - original draft, Writing - review \& editing. Amélia M Silva: Conceptualization, Project administration, Methodology, Resources, Supervision, Formal analysis, Data curation, Visualization, Writing - 
original draft, Writing - review \& editing.

\section{Declaration of Competing Interest}

The authors declare that they have no known competing financial interests or personal relationships that could have appeared to influence the work reported in this paper.

\section{Acknowledgments}

The authors thank to ERVITAL ${ }^{\circledR}$ (Plantas Aromáticas e Medicinais, Lda; Mezio, Portugal) for providing the plants; to the UTAD-Botanical Garden for the help with botanical identification.

\section{Appendix A. Supplementary data}

Supplementary data to this article can be found online at https:// doi.org/10.1016/j.foodchem.2020.127362.

\section{References}

Andreani, T., Kiill, C. P., de Souza, A. L. R., Fangueiro, J. F., Fernandes, L., Doktorovova, S., ... Silva, A. M. (2014). Surface engineering of silica nanoparticles for oral insulin delivery: Characterization and cell toxicity studies. Colloids and Surfaces BBiointerfaces, 123, 916-923.

Chizzola, R., Michitsch, H., \& Franz, C. (2008). Antioxidative properties of Thymus vulgaris leaves: Comparison of different extracts and essential oil chemotypes. Journal of Agricultural and Food Chemistry, 56(16), 6897-6904.

Daliu, P., Santini, A., \& Novellino, E. (2019). From pharmaceuticals to nutraceuticals: Bridging disease prevention and management. Expert Review of Clinical Pharmacology, 12(1), 1-7.

Ferreira, S. S., Silva, A. M., \& Nunes, F. M. (2018). Citrus reticulata Blanco peels as a source of antioxidant and anti-proliferative phenolic compounds. Industrial Crops and Products, 111, 141-148.

Ferreira, S. S., Silva, P., Silva, A. M., \& Nunes, F. M. (2020). Effect of harvesting year and elderberry cultivar on the chemical composition and potential bioactivity: A threeyear study. Food Chemistry, 302, 125366.

Gavarić, N., Kladar, N., Mišan, A., Nikolić, A., Samojlik, I., Mimica-Dukić, N., \& Božin, B. (2015). Postdistillation waste material of thyme (Thymus vulgaris L., Lamiaceae) as a potential source of biologically active compounds. Industrial Crops and Products, 74, 457-464.

Hao, Y., Xie, T., Korotcov, A., Zhou, Y., Pang, X., Shan, L., ... Gu, X. (2009). Salvianolic acid $B$ inhibits growth of head and neck squamous cell carcinoma in vitro and in vivo via cyclooxygenase-2 and apoptotic pathways. Int J Cancer, 124(9), 2200-2209.

Janicsák, G., Veres, K., Zoltán Kakasy, A., \& Máthé, I. (2006). Study of the oleanolic and ursolic acid contents of some species of the Lamiaceae. Biochemical Systematics and Ecology, 34(5), 392-396.

Jia, Z., Tang, M. C., \& Wu, J. M. (1999). The determination of flavonoid contents in mulberry and their scavenging effects on superoxide radicals. Food Chemistry, 64(4), 555-559.

Khouya, T., Ramchoun, M., Hmidani, A., Amrani, S., Harnafi, H., Benlyas, M., ... Alem, C. (2015). Anti-inflammatory, anticoagulant and antioxidant effects of aqueous extracts from Moroccan thyme varieties. Asian Pacific Journal of Tropical Biomedicine, 5(8), 636-644.

Kindl, M., Blazekovic, B., Bucar, F., \& Vladimir-Knezevic, S. (2015). Antioxidant and Anticholinesterase Potential of Six Thymus Species. Evidence-Based Complementary and Alternative Medicine.

Kozics, K., Klusova, V., Srancikova, A., Mucaji, P., Slamenova, D., Hunakova, L., ... Horvathova, E. (2013). Effects of Salvia officinalis and Thymus vulgaris on oxidantinduced DNA damage and antioxidant status in HepG2 cells. Food Chemistry, 141(3), 2198-2206.

Leal, F., Taghouti, M., Nunes, F. M., Silva, A. M., Coelho, A. C., \& Matos, M. (2017) Thymus Plants: A Review-Micropropagation, Molecular and Antifungal Activity. In H. A. El-Shemy (Ed.). Active Ingredients from Aromatic and. Medicinal Plants): InTech.

Lundgren, L., \& Stenhagen, G. (1982). Leaf volatiles from Thymus vulgaris, T. serpyllum, T. praecox, T. pulegioides and T. x citriodorus (Labiatae). Nordic Journal of Botany, 2(5), 445-452.

Machado, M., Felizardo, C., Fernandes-Silva, A. A., Nunes, F. M., \& Barros, A. (2013). Polyphenolic compounds, antioxidant activity and L-phenylalanine ammonia-lyase activity during ripening of olive cv, "Cobrancosa" under different irrigation regimes. Food Research International, 51(1), 412-421.
Martins-Gomes, C., Souto, E. B., Cosme, F., Nunes, F. M., \& Silva, A. M. (2019). Thymus carnosus extracts induce anti-proliferative activity in Caco-2 cells through mechanisms that involve cell cycle arrest and apoptosis. Journal of Functional Foods, 54, $128-135$.

Martins-Gomes, C., Taghouti, M., Schäfer, J., Bunzel, M., Silva, A. M., \& Nunes, F. M. (2018). Chemical characterization and bioactive properties of decoctions and hydroethanolic extracts of Thymus carnosus Boiss. Journal of Functional Foods, 43, $154-164$.

Martins, N., Barros, L., Santos-Buelga, C., Silva, S., Henriques, M., \& Ferreira, I. C. F. R. (2015). Decoction, infusion and hydroalcoholic extract of cultivated thyme: Antioxidant and antibacterial activities, and phenolic characterisation. Food Chemistry, 167, 131-137.

Nabavi, S. M., Marchese, A., Izadi, M., Curti, V., Daglia, M., \& Nabavi, S. F. (2015). Plants belonging to the genus Thymus as antibacterial agents: From farm to pharmacy. Food Chemistry, 173, 339-347.

Nikolić, M., Glamočlija, J., Ferreira, I. C. F. R., Calhelha, R. C., Fernandes, Â., Marković, T., ... Soković, M. (2014). Chemical composition, antimicrobial, antioxidant and antitumor activity of Thymus serpyllum L., Thymus algeriensis Boiss. and Reut and Thymus vulgaris L. essential oils. Industrial Crops and Products, 52, 183-190.

Pacifico, S., Piccolella, S., Papale, F., Nocera, P., Lettieri, A., \& Catauro, M. (2016). A polyphenol complex from Thymus vulgaris L. plants cultivated in the Campania Region (Italy): New perspectives against neuroblastoma. Journal of Functional Foods, 20, 253-266.

Pereira, E., Barros, L., Antonio, A. L., Cabo Verde, S., Santos-Buelga, C., \& Ferreira, I. C. F. R. (2016). Infusions from Thymus vulgaris L. treated at different gamma radiation doses: Effects on antioxidant activity and phenolic composition. LWT, 74, 34-39.

Pereira, O. R., Macias, R. I. R., Perez, M. J., Marin, J. J. G., \& Cardoso, S. M. (2013). Protective effects of phenolic constituents from Cytisus multiflorus, Lamium album L. and Thymus citriodorus on liver cells. Journal of Functional Foods, 5(3), 1170-1179.

Pereira, O. R., Peres, A. M., Silva, A. M. S., Domingues, M. R. M. \& Cardoso, S. M. (2013). Simultaneous characterization and quantification of phenolic compounds in Thymus $x$ citriodorus using a validated HPLC-UV and ESI-MS combined method. Food Research International, 54(2), 1773-1780.

Petrović, S., Ušjak, L., Milenković, M., Arsenijević, J., Drobac, M., Drndarević, A., \& Niketić, M. (2017). Thymus dacicus as a new source of antioxidant and antimicrobial metabolites. Journal of Functional Foods, 28, 114-121.

Qin, T., Rasul, A., Sarfraz, A., Sarfraz, I., Hussain, G., Anwar, H., ... Li, X. (2019). Salvianolic acid A \& B: Potential cytotoxic polyphenols in battle against cancer via targeting multiple signaling pathways. Int J Biol Sci, 15(10), 2256-2264.

Rita, I., Pereira, C., Barros, L., \& Ferreira, I. C. F. R. (2018). Exploring reserve lots of Cymbopogon citratus, Aloysia citrodora and Thymus $\times$ citriodorus as improved sources of phenolic compounds. Food Chemistry, 257, 83-89.

Sacchetti, G., Maietti, S., Muzzoli, M., Scaglianti, M., Manfredini, S., Radice, M., \& Bruni, R. (2005). Comparative evaluation of 11 essential oils of different origin as functional antioxidants, antiradicals and antimicrobials in foods. Food Chemistry, 91(4), 621-632.

Severino, P., Andreani, T., Jager, A., Chaud, M. V., Santana, M. H. A., Silva, A. M., \& Souto, E. B. (2014). Solid lipid nanoparticles for hydrophilic biotech drugs: Optimization and cell viability studies (Caco-2 \& HEPG-2 cell lines). European Journal of Medicinal Chemistry, 81, 28-34.

Shahidi, F. (2009). Nutraceuticals and functional foods: Whole versus processed foods Trends in Food Science \& Technology, 20(9), 376-387.

Silva, A. M., Martins-Gomes, C., Coutinho, T. E., Fangueiro, J. F., Sanchez-Lopez, E. Pashirova, T. N., ... Souto, E. B. (2019). Soft Cationic Nanoparticles for Drug Delivery: Production and Cytotoxicity of Solid Lipid Nanoparticles (SLNs). Applied Sciences, 9(20), 4438

Sreejayan, \& Rao, M. N. A. (1997). Nitric oxide scavenging by curcuminoids. Journal of Pharmacy and Pharmacology, 49(1), 105-107.

Taghouti, M., Martins-Gomes, C., Schafer, J., Felix, L. M., Santos, J. A., Bunzel, M., ... Silva, A. M. (2018). Thymus pulegioides L. as a rich source of antioxidant, anti-proliferative and neuroprotective phenolic compounds. Food \& Function, 9(7), 3617-3629.

Taghouti, M., Martins-Gomes, C., Schäfer, J., Santos, J. A., Bunzel, M., Nunes, F. M., \& Silva, A. M. (2020). Chemical Characterization and Bioactivity of Extracts from Thymus mastichina: A Thymus with a Distinct Salvianolic Acid Composition. Antioxidants, 9(1), 34.

Thompson, J. D., Chalchat, J. C., Michet, A., Linhart, Y. B., \& Ehlers, B. (2003). Qualitative and quantitative variation in monoterpene co-occurrence and composition in the essential oil of Thymus vulgaris chemotypes. Journal of Chemical Ecology, 29(4), 859-880.

Vigo, E., Cepeda, A., Gualillo, O., \& Perez-Fernandez, R. (2004). In-vitro anti-inflammatory effect of Eucalyptus globulus and Thymus vulgaris: Nitric oxide inhibition in J774A.1 murine macrophages. Journal of Pharmacy and Pharmacology, 56(2), 257-263.

Wang, Q.-L., Wu, Q., Tao, Y.-Y., Liu, C.-H., \& El-Nezami, H. (2011). Salvianolic acid B modulates the expression of drug-metabolizing enzymes in HepG2 cells. Hepatobiliary \& Pancreatic Diseases International, 10(5), 502-508. 